\title{
Ultrastructural features of neuroblastic tumours in relation to morphological, and molecular findings; a retrospective review study
}

\author{
Elizabeth Latimer ${ }^{2}$, Glenn Anderson ${ }^{2}$ and Neil James Sebire ${ }^{1,2,3^{*}}$
}

\begin{abstract}
Background: Neuroblastoma is the most common solid tumour of infancy and is responsible for $15 \%$ of childhood cancer deaths. Presence of amplified MYCN in neuroblastoma is associated with poor prognosis and rapid tumour progression. The aim of this study was to examine and compare the ultrastructural features of high-risk MYCN amplified neuroblastomas, with lower-risk non-MYCN amplified tumours.
\end{abstract}

Methods: This was a retrospective study evaluating archival diagnostic tissue samples, in which Fluorescence in-situ hybridisation (FISH) had been used at diagnosis to establish MYCN status. 22 (11 MYCN amplified tumours and 11 non-MYCN amplified) tumours of similar light microscopic appearance (poorly differentiated neuroblastoma) were then selected for ultrastructural examination.

Results: There is a relationship between ultrastructural features in neuroblastoma and MYCN status, although with marked overlap between groups. MYCN amplified tumours generally exhibited a 'less differentiated' ultrastructural phenotype, with significantly smaller neurotubules (NT) in the cell body $(p<0.002)$. Non-MYCN amplified tumours show increased features of neuronal differentiation, with fewer neurosecretory granules (NSG) and NT in the cytoplasm.

Conclusions: MYCN amplification is associated with a less differentiated ultrastructural phenotype, and lack of MYCN amplification with relative ultrastructural neuronal differentiation.

Keywords: Neuroblastoma, Ultrastructure, Electron microscopy, Molecular biology, MYCN

\section{Background}

Neuroblastoma is the most common solid tumour of childhood, and with an incidence of 1 in 10,000, it is responsible for $15 \%$ of childhood cancer deaths [1,2]. Neuroblastoma originates from primordial neural crest cells, often occurring in sympathetic ganglia and chromaffin cells of the adrenal medulla; however it can occur anywhere along the sympathetic chain, including the pelvis, neck and brain [3]. Neuroblastoma is classed as one of the 'small blue round cell tumours' and by routine light microscopy demonstrates sheets and nests of small primitive appearing cells with speckled, hyperchromatic nuclei, scant cytoplasm and poorly defined cell borders. The nested background demonstrates faintly eosinophillic

\footnotetext{
* Correspondence: n.sebire@ucl.ac.uk

'Institute of Child Health, UCL, London, UK

${ }^{2}$ Department of Histopathology, UCL, London, UK

Full list of author information is available at the end of the article
}

fibrillary neuropil, a mass of interwoven nerve endings, dendrites and other neurone components [4].

Prognosis can vary markedly, from fatal to spontaneous regression [1,5]. Molecular biology findings are associated with adverse prognosis, the best studied of which is amplification of the MYCN oncogene. MYCN is a member of the $M Y C$ proto-oncogene family, and is a nuclear transcription factor not normally found in adult tissues. [6,7]. Presence of $M Y C N$ amplification is associated with adverse outcome and tumour progression $[8,9]$.

Ultrastructural features of neuroblastic tumours are well-described [10-14] but there are no data regarding ultrastructural findings specifically in relation to $M Y C N$ status. This study examines the ultrastructure of high-risk $M Y C N$ amplified neuroblastomas, compared with low-risk non-MYCN amplified tumours to test the hypothesis that neuroblastomas will have ultrastructural differences related to their molecular characteristics. 


\section{Methods}

A search of the histopathology diagnostic archive was made to identify neuroblastomas (Neuroblastic tumour, neuroblastoma (Schwannian stroma poor), poorly differentiated subtype' based on light microscopic assessment) with potentially viable material stored for electron microscopic examination and $M Y C N$ status assessment performed as part of routine clinical care. $25 M Y C N$ amplified, and 25 matched non-MYCN amplified, neuroblastomas were initially identified, of which 22, 11 cases in each group, were suitable for ultrastructural analysis. Suitability was judged based on the amount of necrosis present and tumour preservation observed at ultrastructural level. The number of cases was considered statistically significant for the study with a power of $80 \%$ to detect differences of $25 \%$ between groups.

Samples were initially confirmed as poorly differentiated neuroblastomas by light microscopy using $3 \mu \mathrm{m}$ formalin fixed paraffin embedded tissue and a Haematoxylin and Eosin stain. Sectioning and staining were carried out by standard methods as per standard [14]. Further confirmation of neuroblastoma was by the use of immunohistochemistry for NB84 and CD56 [4]. Fluorescence in-situ Hybridisation (FISH) was performed as part of routine clinical care using a standard protocol [15]. We used a commercial probe available from Abbott Molecular, USA, with each new batch validated in the laboratory before use on patient material. (Vysis LSI N-MYC (2p24) SpectrumGreen/CEP 2 SpectrumOrange Probe (Abbott Molecular, USA)). Cells hybridized using this dual-colour probe show multiple green signals when $\mathrm{MYCN}$ amplification is present. When investigating MYCN status by Fluorescence In Situ Hybridization (FISH), MYCN amplification is defined as $>4$-fold MYCN signals compared to $2 \mathrm{p}$ reference probe signals. MYCN amplification can occur as either intrachromosomal homogeneously staining regions (HSRs) or as genetically unstable extrachromosomal double minutes (DMs) [16].

For ultrastructural analysis, samples were fixed in 2.5\% glutaraldehyde in $0.1 \mathrm{M}$ cacodylate buffer with secondary fixation in $1.0 \%$ osmium tetroxide. Tissues were dehydrated in graded ethanol and transferred to propylene oxide and finally infiltrated and embedded in Agar 100 epoxy resin. 90 nanometre ultra-thin sections were cut using a Diatome diamond knife on a Leica Ultracut UCT ultramicrotome. Sections were picked up on copper grids and stained with alcoholic uranyl acetate and Reynold's lead citrate. The samples were then viewed with JEOL (UK) Ltd, JEM-1400 120 kV Transmission Electron Microscope. All measurements were carried out using the JEOL microscope and Advanced Media Technologies Inc (AMT) software and were recorded with the images. Initial observations included overall tumour architecture, cell adhesion and stroma and subsequent quantitative observations included the most characteristic and frequently seen features of neuroblasts, cytoplasmic (neuritic) processes and the neurosecretory granules (NSG). The cell processes usually contain neurotubules (NT), and intermediate filaments [17]. The position of these tubules within the cell, and whether the tubules were in the cytoplasm, or within the processes was observed. The number and diameters $(\mathrm{nm})$ of the neurotubules (NT) present in the cell body were measured in multiple well preserved and viable cells per sample (total 45 measurements in the 11 MYCN amplified group and 48 measurements in the 11 non-MYCN amplified group). NSG are small, round, membrane bound secretory granules, which contain a characteristic central dense core surrounded by a peripheral halo [18]. The number of NSG present in the cell body were counted and their diameter measured. The numbers of the NSG and NT were measured only within the cell body, as it was not possible to track the cell processes using a 2-D plane. All diameter measurements were carried out using the AMT software and all measurements were in nanometres (nm).

All statistical analyses were calculated with SPSS (Statistical Package for the Social Sciences), version 19.0, IBM, UK. The parametric student T-test and the nonparametric Mann-Whitney $U$ test were used to compare distributions between groups as appropriate. All results were considered statistically significant at $\mathrm{p}<0.05$. Ethical approval was obtained from the National Research Ethics Service (NRES) committee London, Bloomsbury (REC reference number 11/LO/1175). Approval was gained from Great Ormond Street NHS Hospital Foundation Trust and Institute of Child Health (UCL) (R\&D number 10MH31) and the study was funded by Great Ormond Street Children's Charity (V0907). All cases used were non-identifiable, archival cases.

\section{Results}

The mean median age of patients across both groups was 27 (range 1-144) months, with no significant difference in age between the $M Y C N$ amplified and non-amplified groups $(\mathrm{P}=0.55)$. Ultrastructural morphological examination demonstrated that $M Y C N$ amplified tumours had a subjectively 'less differentiated' ultrastructural appearance, with scanty neuritic processes, which contained fewer NSG and NT. The non-MYCN amplified tumours had a more differentiated ultrastructural appearance, with frequent cell processes all appearing well developed with abundant NSG and NT, (Figures 1 and 2).

There were significantly fewer NSG and NT in the cell body of the non-MYCN amplified neuroblastomas, but with markedly overlapping distributions. The mean number of NSG in the cell body was 6.4/cell for the $M Y C N$ amplified group versus $4.1 /$ cell for the non- $M Y C N$ amplified group $(\mathrm{P}<0.001)$. The mean number of NT in the cell body of the $M Y C N$ amplified group was 21.8/ cell compared to a mean of $17.7 /$ cell for the non- $M Y C N$ amplified 


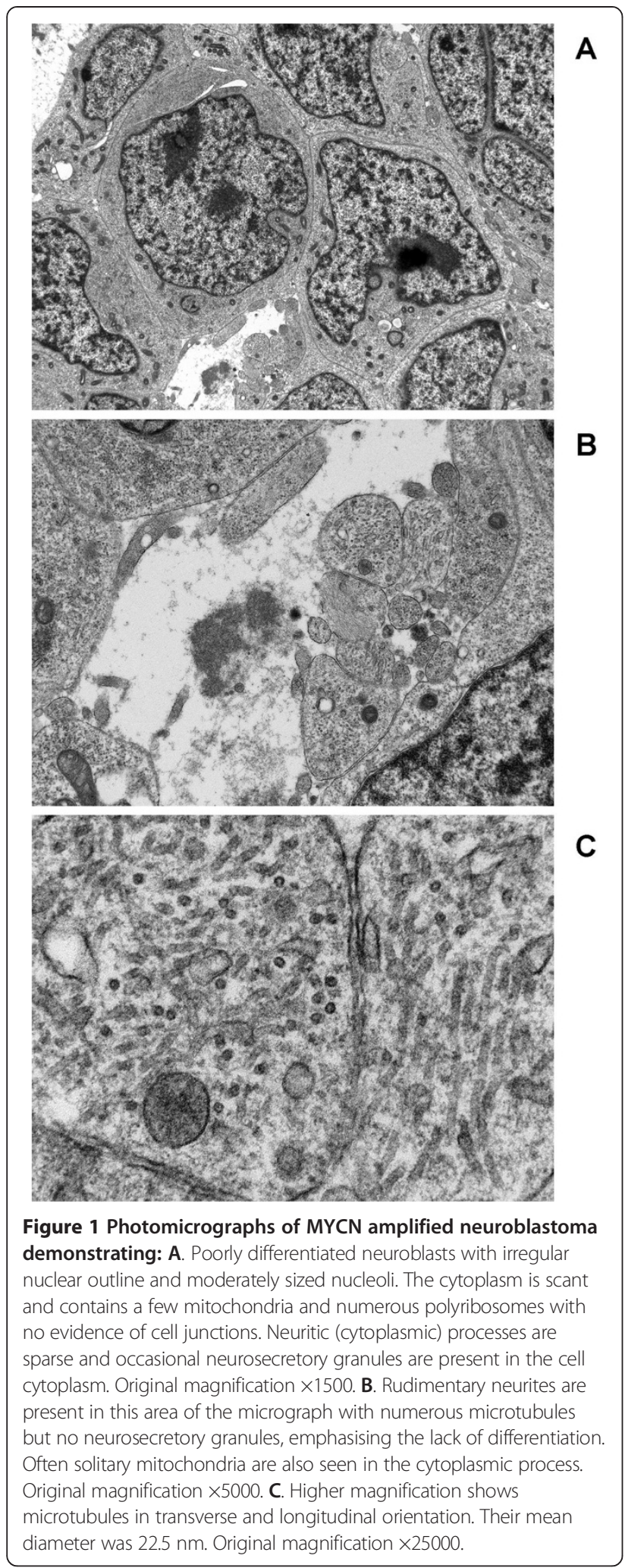

group $(\mathrm{P}<0.001)$. The mean NSG diameters were not significantly different between groups. $(P=0.88)$, mean diameter of all cases, $98 \mathrm{~nm}$. However, the mean diameter of
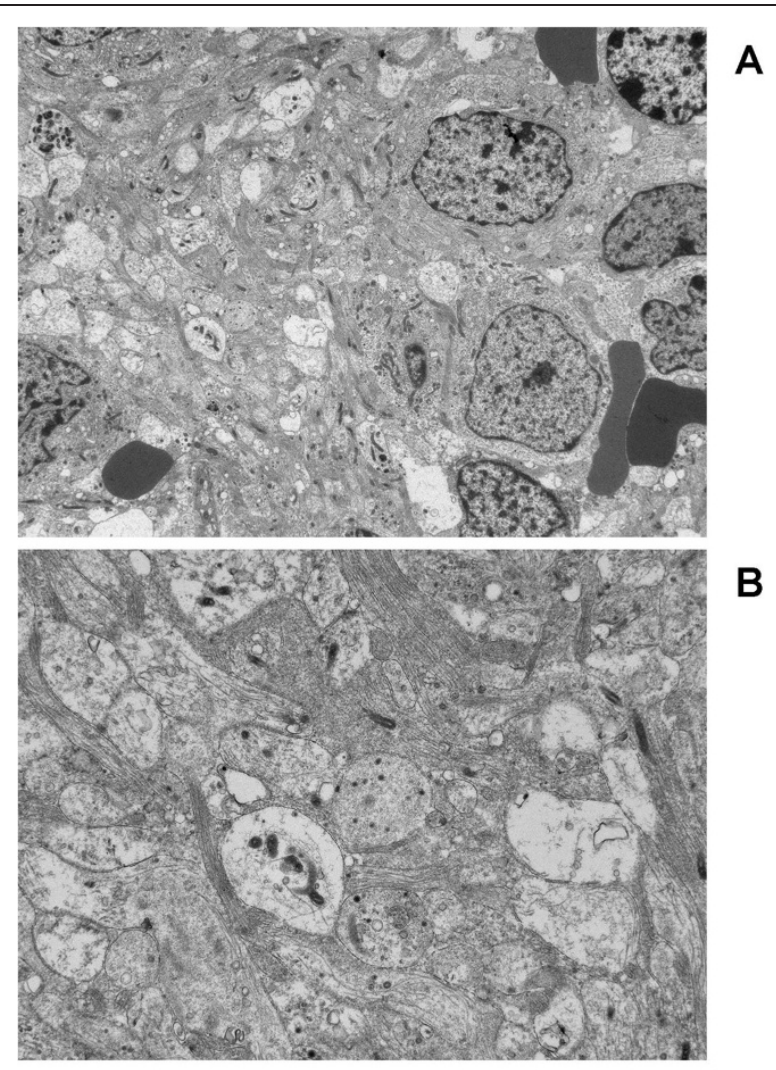

B

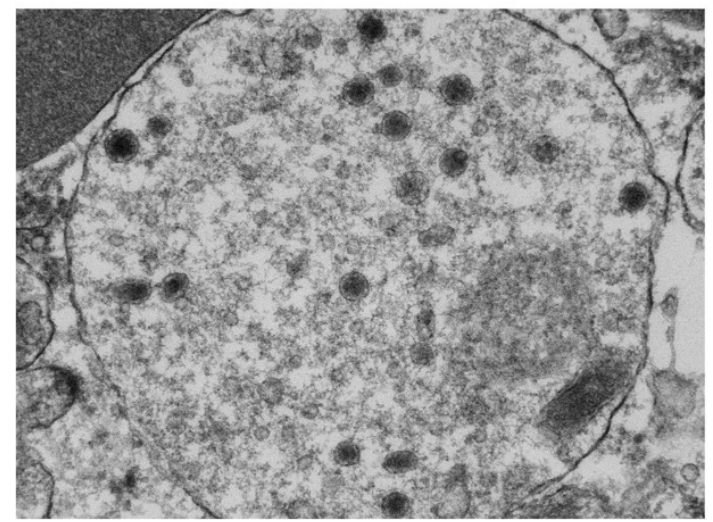

C

Figure 2 Photomicrographs of non-MYCN amplified neuroblastoma demonstrating: A. Neuroblastoma with widespread neuritic processes. Tumour cells are small and round and do not show ganglion cell differentiation at this stage. Original magnification $\times 1000$. B. The image demonstrates abundant sheaves of microtubules and neurites in transverse section with many electron dense neurosecretory granules. Original magnification $\times 3000$. C. A high power view of a neurite process with dense-core, neurosecretory granules with a characteristic peripheral halo. The mean diameter of the granules in all cases was $98 \mathrm{~nm}$. Original magnification $\times 15000$.

NT in the $M Y C N$ amplified group was significantly less than the non-MYCN amplified group (22.5 $\mathrm{nm}$ versus $23.8 \mathrm{~nm}$ respectively $(\mathrm{P}<0.002)$ (Figure 3$)$. 

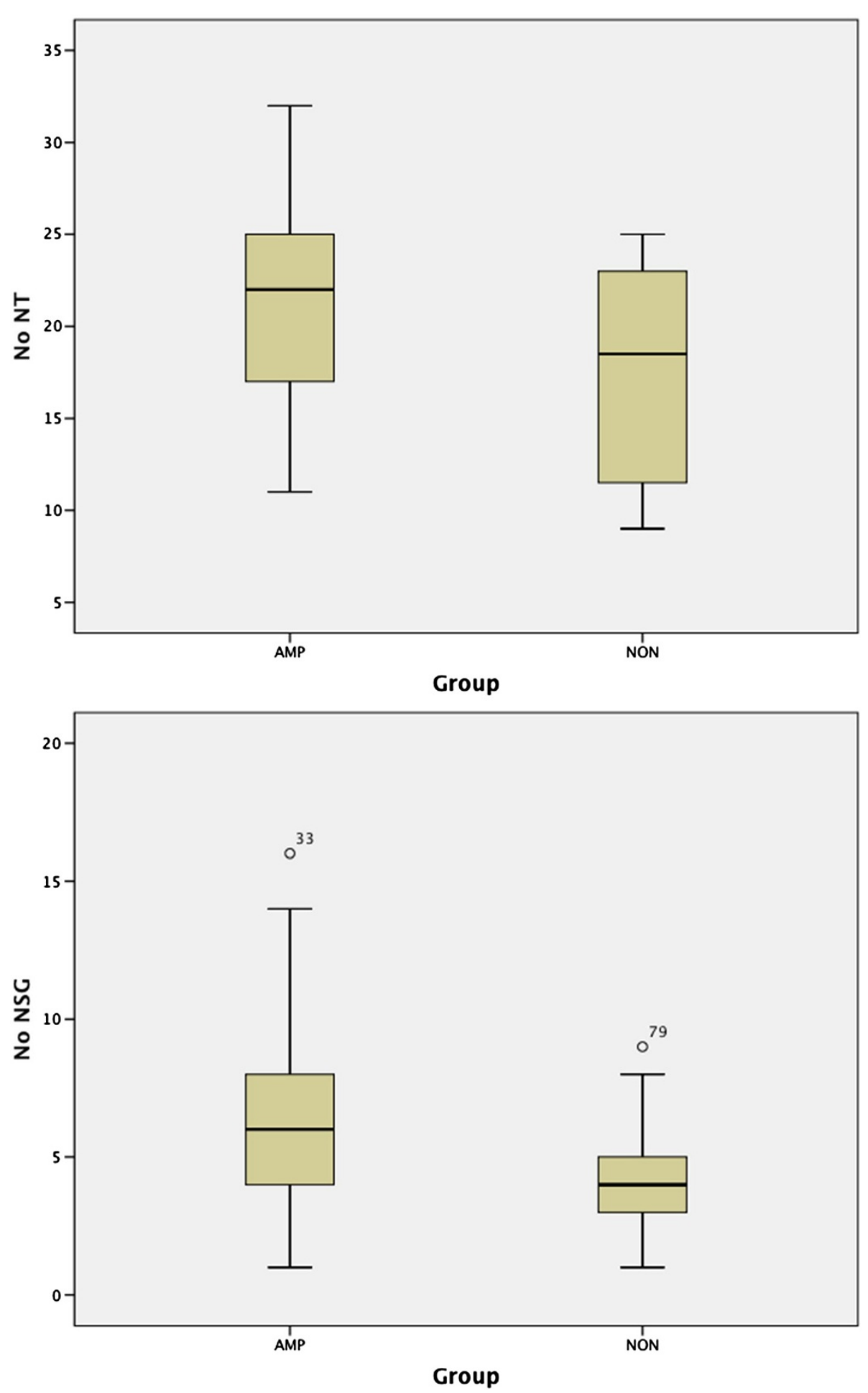

Figure 3 Box-whisker plots demonstrating distribution of number of neurotublues (NO NT) and number of neurosecretory granules (NO NSG) per cell examined in MYCN amplified (AMP) versus non-MYCN amplified (NON) morphologically poorly differentiated neuroblastomas.

\section{Discussion}

The findings of this study have demonstrated that there are significant ultrastructural morphological differences between $M Y C N$-amplified and non-MYCN-amplified neuroblastomas, including a statistically significant reduction in diameter of NT, and significantly more NSG and NT in the cell body of $M Y C N$-amplified tumours. These differences may be explained by the finding that 
MYCN amplified cells appear less differentiated, and therefore the NSG and NT in the cell bodies have not yet extended into cell processes. Additionally, since $M Y C N$ amplified tumours appear less differentiated, the smaller size of their NT may represent tubules in these tumours being less well-developed.

$M Y C N$ is involved in the expression of many target genes, which regulate a range of cellular processes, including cell growth, proliferation, differentiation, and apoptosis [19]. MYCN is primarily an embryonic developmental gene, whose normal expression is specifically restricted (in humans and mice) to certain tissues in the developing embryo. MYCN is specifically found in the neuroepithelium, and also in the developing lung, heart kidney and intestine $[7,20]$. Primary functions of $M Y C N$ are proposed to be related to control of cell proliferation and enabling cells to remain in relatively undifferentiated states [19]. Over expression of $M Y C N$ in the neural crest results in an increased generation of neurons but down regulation of $M Y C N$ is required for these neurons to become terminally differentiated $[21,22]$. In combination, these findings suggest that MYCN signalling is important in maintaining cells in an undifferentiated state and that down regulation of $M Y C N$ can lead to neuronal differentiation [6]. The present ultrastructural findings support these suggested roles since $M Y C N$ amplified cells had a morphologically less differentiated appearance, with associated morphometric changes.

Increased MYCN expression keeps cells in an undifferentiated and proliferative state [6]. Therefore, the hypothesis has been raised that blocking $M Y C N$ expression or its action could lead to less aggressive tumours, and lead to new therapies for high-risk patients [23]. Differentiation as a target for therapy has been investigated and several groups are attempting to down regulate $M Y C N$ expression as a treatment in high-risk $M Y C N$ amplified neuroblastoma. Several agents have been investigated, of which 13cis-retinoic acid shows the most promise, showing neurite outgrowth and differentiation of human neuroblastoma cells in vitro and in vivo [6]. These results are in accordance with the current ultrastructural findings, that lowerrisk tumours show substantial neurite outgrowth and were morphologically more differentiated, despite being within the poorly differentiated light microscopy subgroup of neuroblastomas.

The present study demonstrated a significant difference in both the size and number of neurotubules within $M Y C N$ amplified tumours compared to the non- $M Y C N$ amplified tumours, which has not been reported previously. Microtubules and intermediate filaments, of which neurotubules are an example, are involved in intracellular transport and it can be hypothesised that if a cell has a more patent network of tubules and filaments then drug transport may occur more efficiently. This remains entirely speculative but may offer a possible explanation regarding the association of $M Y C N$ amplified tumours with adverse outcome.

Whilst markers of differentiation, such as dense core neurosecretory granules and neuritic processes, may be identified, and the neuropil seen on light microscopy is identified as neuritic processes with NSG, poorly differentiated neuroblastomas have previously been reported to generally show no major ultrastructural variations related to outcome not identified by light microscopy, although there may be an association between low numbers of NSG and adverse clinical course [10-13].

\section{Conclusions}

There are ultrastructural morphological differences in neuroblastoma, dependent upon $M Y C N$ amplification status. The data is limited by the small study size but provides the first data in this area, and is consistent with current evidence on functioning of $M Y C N$, with increased $M Y C N$ expression being associated with a less differentiated phenotype.

\section{Competing interests}

The authors declare that they have no competing interests.

\section{Authors' contributions}

$\mathrm{BL}$ and GA carried out the electron microscopic examination and interpretation. NJS, BL and GA participated in the design of the study and performed the statistical analysis. NJS conceived of the study, and participated in its design and coordination and helped to draft the manuscript. All authors drafted, read and approved the final manuscript.

\section{Acknowledgements}

The authors would like to thank: Dr Anthony Madgwick, Dr lan Patterson, Dr Anthony Warford and the University of Westminster and Dr Mario Cortina Borja at the Institute for Child Health for academic support for BL; and all the staff in the Histopathology Department at Great Ormond Street Hospital. NJS is part supported by the NIHR GOSH/UCL BRC and GOSHCC.

\section{Funding}

NJS is part supported by GOSHCC and the National Institute of Health Research GOSH/UCL Biomedical Research Centre.

\section{Author details}

${ }^{1}$ Institute of Child Health, UCL, London, UK. Department of Histopathology, UCL, London, UK. ${ }^{3}$ Great Ormond Street Hospital for Children Foundation Trust, London WC1N 3JH, UK.

Received: 6 January 2014 Accepted: 19 March 2014

Published: 31 March 2014

\section{References}

1. Schwab M, Westermann F, Hero B, Berthold F: Neuroblastoma: biology and molecular and chromosomal pathology. Lancet Oncol 2003, 4:472-480.

2. Park JR, Eggert A, Caron H: Neuroblastoma: biology, prognosis, and treatment. Hematol/Oncol Clin N Am 2010, 24:65-86.

3. Weinstein $J$, Katzenstein HM, Cohn SL: Advances in the diagnosis and treatment of neuroblastoma. Oncologist 2003, 8:278-292.

4. Sebire NJ, Malone M, Ashworth M, Jacques TS: Tumours. Chapter 6. In Diagnostic Pediatric Surgical Pathology. London: Churchill Livingstone; 2010:165-172.

5. Mueller S, Matthay KK: Neuroblastoma: biology and staging. Curr Oncol Rep 2009, 11:431-438.

6. Westermark UK, Wilhelm M, Frenzel A, Henriksson MA: The MYCN oncogene and differentiation in neuroblastoma. Semin Canc Biol 2011, 21:256-266. 
7. Zimmerman KA, Yancopoulos GD, Collum RG, Smith RK, Kohl NE, Denis KA, Nau MM, Witte ON, Toran-Allerand D, Gee CE, Minna JD, Alt FW: Differential expression of myc family genes during murine development. Nature 1986, 319:780-783.

8. Tang XX, Zhao H, Kung B, Kim DY, Hicks SL, Cohn SL, Cheung NK, Seeger RC, Evans AE, Ikegaki $N$ : The MYCN enigma: significance of MYCN expression in neuroblastoma. Canc Res 2006, 66:2826-2833.

9. Hiyama E, Hiyama K, Ohtsu K, Yamaoka H, Fukuba I, Matsuura Y, Yokoyama T: Biological characteristics of neuroblastoma with partial deletion in the short arm of chromosome 1. Med Pediat Oncol 2001, 6:67-74.

10. Yanagisawa M: Electron microscopic study of neuroblastoma. Paediatr Univ Tokyo 1970, 17:29-39.

11. Romansky SG, Crocker DW, Shaw KN: Ultrastructural studies on neuroblastoma: evaluation of cytodifferentiation and correlation of morphology and biochemical and survival data. Cancer 1978, 42:2392-2398.

12. Taxy JB: Electron microscopy in the diagnosis of neuroblastoma. Arch Pathol Lab Med 1980, 104:355-360.

13. Shimada H: Transmission and scanning electron microscopic studies on the tumors of neuroblastoma group. Acta Pathol Jpn 1982, 32:415-426.

14. Hicks MJ, Mackay B: Comparison of ultrastructural features among neuroblastic tumors: maturation from neuroblastoma to ganglioneuroma. Ultrastruct Pathol 1995, 19:311-322.

15. Bancroft JD, Gamble M: Theory and Practice of Histological Techniques. Sixthth edition. London: Churchill Livingstone; 2008:126-127.

16. Taylor CP, Bown NP, McGuckin AG, Lunec J, Malcolm AJ, Pearson AD, Sheer D: Fluorescence in situ hybridization techniques for the rapid detection of genetic prognostic factors in neuroblastoma. United Kingdom Children's Cancer Study Group. Br J Canc 2000, 83:40-49.

17. Lundberg $G$, Rosengren $A H$, Håkanson $U$, Stewénius $H$, Jin $Y$, Stewénius $Y$, Påhlman S, Gisselsson D: Binomial mitotic segregation of MYCN-carrying double minutes in neuroblastoma illustrates the role of randomness in oncogene amplification. PLoS One 2008, 3:e3099.

18. Erlandson RA: Diagnostic Transmission electron Microscopy of Tumors. New York: Raven Press; 1994:555-562.

19. Eilers M, Eisenman RN: MYC's broad reach. Genes Dev 2008, 22:2755-2766.

20. Stanton BR, Perkins AS, Tessarollo L, Sassoon DA, Parada LF: Loss of N-myc function results in embryonic lethality and failure of the epithelial component of the embryo to develop. Genes Dev 1992, 6:2235-2247.

21. Wakamatsu Y, Watanabe $Y$, Nakamura H, Kondoh H: Regulation of the neural crest cell fate by $\mathrm{N}$-myc: promotion of ventral migration and neuronal differentiation. Development 1997, 197(124):1953-1962.

22. Alam G, Cui H, Shi H, Yang L, Ding J, Mao L, Maltese WA, Ding HF: MYCN promotes the expansion of Phox2B-positive neuronal progenitors to drive neuroblastoma development. Am J Pathol 2009, 175:856-866.

23. Gustafson WC, Matthay KK: Progress towards personalized therapeutics: biologic- and risk-directed therapy for neuroblastoma. Exp Rev Neurotherapeutics 2011, 11:1411-1423.

Cite this article as: Latimer et al:: Ultrastructural features of neuroblastic tumours in relation to morphological, and molecular findings; a retrospective review study. BMC Clinical Pathology 2014 14:13.

\section{Submit your next manuscript to BioMed Central and take full advantage of:}

- Convenient online submission

- Thorough peer review

- No space constraints or color figure charges

- Immediate publication on acceptance

- Inclusion in PubMed, CAS, Scopus and Google Scholar

- Research which is freely available for redistribution

Submit your manuscript at www.biomedcentral.com/submit
C Biomed Central 